Article

\title{
Pitting Corrosion of Natural Aged Al-Mg-Si Extrusion Profile
}

\author{
Quanmei Guan ${ }^{1}$, Jing Sun ${ }^{1}$, William Yi Wang ${ }^{2, *} \mathbb{( D}$, Junfeng Gao ${ }^{2}$, Chengxiong Zou ${ }^{2} \mathbb{D}$, \\ Jun Wang ${ }^{2}{ }^{\oplus}$, Bin Tang ${ }^{2}$, Hongchao Kou ${ }^{2}$, Haisheng Wang ${ }^{1}$, Jianying Hou ${ }^{1}$, Jun Gao ${ }^{1}$, \\ Jijun $\mathrm{Ma}^{1, *}$ and Jinshan $\mathrm{Li}^{2, *}$ \\ 1 CRRC Tangshan Co., LTD, Tangshan 063035, China; sjc-guanquanmei@tangche.com (Q.G.); \\ sjc-sunjing@tangche.com (J.S.); wanghaisheng@tangche.com (H.W.); sjc-houjianying@tangche.com (J.H.); \\ sjc-gaojun@tangche.com (J.G.) \\ 2 State Key Laboratory of Solidification Processing, Northwestern Polytechnical University, \\ Xi'an 710072, China; gaojunfeng25@foxmail.com (J.G.); zcx2016@mail.nwpu.edu.cn (C.Z.); \\ nwpuwj@nwpu.edu.cn (J.W.); toby198489@163.com (B.T.); hchkou@nwpu.edu.cn (H.K.) \\ * Correspondence: wywang@nwpu.edu.cn (W.Y.W.); Sjc-majijun@tangche.com (J.M.); ljsh@nwpu.edu.cn (J.L.)
}

Received: 2 March 2019; Accepted: 27 March 2019; Published: 2 April 2019

\begin{abstract}
With the quick development of the high-speed railway and the service of the China Railway High-speed (CRH) series for almost a decade, one of the greatest challenges is the management/maintenance of these trains in environmental conditions. It is critical to estimate pitting damage initiation and accumulation and set up a corresponding database in order to support the foundations for interactive corrosion risk management. In this work, the pitting corrosion of a nature-aged commercial 6005A-T6 aluminum extrusion profile for 200 days was studied comprehensively. The heterogeneous microstructures were conventionally identified by the in situ eddy current, suggesting which investigated regions to fabricate samples for. After constant immersion for $240 \mathrm{~h}$ in $3.5 \mathrm{wt} \% \mathrm{NaCl}$, the shapes and depths of the pits were captured and measured by optical microscope $(\mathrm{OM})$ and three-dimensional optical profilometry $(\mathrm{OP})$, providing detailed quantification of uniform pitting corrosion. The typical features of the pits dominated by the distribution of precipitates include the peripheral dissolution of the Al matrix, channeling corrosion, intergranular attack, and large pits in the grains. Due to the high density of continuous anodic and cathodic particles constituted by alloying elements in coarse grains, the number of pits in the coarse grains was the highest while the number in the fine grains was the lowest, indicating that fine grains have the best corrosion resistance. The experimental dataset of the pit depth integrated with its corresponding microstructure would set the benchmark for further modeling of the pit depth and the remaining ductility, in order to manage the damage tolerance of the materials.
\end{abstract}

Keywords: pitting corrosion; natural aging; eddy current; 3D optical profilometry; high-throughput measurement

\section{Introduction}

Age hardenable Al-Mg-Si (6XXX) alloys are widely utilized in the aerospace, transport, automotive, and shipbuilding industries due to their high strength-to-weight ratio, recyclability, and resistance to corrosion [1-3]. They get further preference for industrial application than other series, such as Al-Cu-based (2XXX) and Al-Zn-based (7XXX) alloys, due to the lower amount of alloying element that they have and, thus, their lower cost [4]. Through well-known aging treatments, such as the T6 condition which is described by solid solution in the single phase region $\left(520-540{ }^{\circ} \mathrm{C}\right)$ followed by quenching and artificially aged at a moderate temperature $\left(150-200{ }^{\circ} \mathrm{C}\right)$, their mechanical properties 
can be modulated by the precipitation-hardening mechanism [4,5]. In general, the precipitation sequence of $\mathrm{Al}-\mathrm{Mg}-\mathrm{Si}$ alloys has been reported as [3,5-8]:

$$
\text { SSSS } \rightarrow \text { solute clusters } \rightarrow \text { GP Zones } \rightarrow \beta^{\prime \prime} \rightarrow \beta^{\prime}
$$

Here, SSSS represents the supersaturated solid solution. With the addition of $\mathrm{Cu}$, the precipitation sequence changes to $[7,9]$ :

$$
\text { SSSS } \rightarrow \text { solute clusters } \rightarrow \text { GP Zones } \rightarrow \beta^{\prime \prime}, \mathrm{L} / \mathrm{S} / \mathrm{C}, \mathrm{QP}, \mathrm{QC} \rightarrow \beta^{\prime}, \mathrm{Q}^{\prime} \rightarrow \mathrm{Q}
$$

where $\mathrm{L}, \mathrm{C}, \mathrm{S}$, and $\mathrm{Q}^{\prime}$ are metastable precipitates containing $\mathrm{Cu}$. The $\mathrm{L}$ phase is believed to be a $\mathrm{Q}^{\prime}$ precursor, playing an important effect in strengthening the alloy [7].

Besides improving the mechanical properties of Al-Mg-Si alloys, the presence of $\mathrm{Cu}$ usually enhances precipitation-hardening kinetics, refines the microstructure, and reduces the negative effects of natural aging (NA) $[2,7,10]$. However, NA can significantly lessen the hardening kinetics and the maximum strength obtained in the subsequent artificial aging (AA) of the Al-Mg-Si alloy, which is the so-called negative effect of NA [5]. It has been reported that the negative NA effect is transient and reversed upon long storage times by the dominance of a process beneficial to precipitation in $\mathrm{Al}-\mathrm{Mg}-\mathrm{Si}$ alloys [3]. It is worth mentioning that several weeks or months are required to manufacture the final product from the raw $\mathrm{Al}$ alloys in transport and automobile industries [2,6]. Alloys are unavoidably stored for a period at room temperature, which undergo NA directly after quenching from solution heat treatment and result in two issues that need to be addressed, i.e., reduced formability and the negative NA effect [2,6]. For example, based on the investigations of an $\mathrm{Al}-\mathrm{Mg}-\mathrm{Si}$ alloy influenced by NA for 70 days and pre-treatment at $70{ }^{\circ} \mathrm{C}$ for $16 \mathrm{~h}$ prior to the AA at $175{ }^{\circ} \mathrm{C}$, it was found that $\mathrm{Mg}-\mathrm{Si}$ co-clusters formed during NA and small Guinier-Preston (GP) zones after pre-aging were present [8]. Si-rich clusters formed during NA can neither be dissolved nor grow during subsequent AA, which needs to be modified to enhance age-hardening behavior [6,11]. Similarly, AA7075 alloys naturally aged for 300 days were studied to reveal the effect of grain size on the pitting characteristics, showing that the frequency of the pitting current transients increased with the improved ratio of fine grains while the lifetime and the peak value of the current transient decreased [12].

The precipitates or second phases play an important role in the localized corrosion behavior of $\mathrm{Al}$ alloys, which is called pitting corrosion [13-16]. Pitting corrosion is one of the most destructive forms of corrosion that can lead to the catastrophic failure of structures/equipment, since corrosion damage is a frequent initiation site for cracks [17-20]. Pits can initiate at intermetallic particles resulting in microgalvanic interactions, so their size, quantity, location, continuity, and corrosion potential relative to that of the $\mathrm{Al}$ alloy matrix can influence pitting corrosion behavior $[15,16,21]$. Intermetallic compounds, including $\mathrm{Al}_{2} \mathrm{CuMg}, \mathrm{Al}_{3} \mathrm{Mg}_{2}, \mathrm{Mg}_{2} \mathrm{Si}$, and $\mathrm{MgZn}_{2}$, generally act as the anode and corrode preferentially with the surrounding $\mathrm{Al}$ matrix [16]. On the contrary, compounds such as $\mathrm{Al}_{2} \mathrm{Cu}, \mathrm{AlFeMnSi}, \mathrm{AlCuFeMn}, \mathrm{AlCuFeSi}$, and $(\mathrm{Al}, \mathrm{Cu})_{x}(\mathrm{Fe}, \mathrm{Mn})_{\mathrm{y}} \mathrm{Si}$ are mostly cathode, resulting in the peripheral trenches of the $\mathrm{Al}$ matrix [16].

Since pitting corrosion is one of the most widespread and dangerous forms of localized corrosion in passive materials and is difficult to detect and predict [12], great efforts have been made to develop numerical models and reveal the fundamental mechanisms of pitting corrosion [18-20,22-27]. With the fast growth of the high-speed railway in China reaching to $3 \times 10^{4} \mathrm{~km}$ in 2020 [28] and the service of the China Railway High-speed (CRH) series for almost a decade, one of the greatest challenges is the management and maintenance of these trains in environmental conditions. It is critical to estimate the initiation and propagation of pitting and set up a corresponding database in order to support the foundations for interactive corrosion risk management. Unfortunately, there is not much information/data showing the effect of NA on pitting corrosion and the mechanical properties of the $\mathrm{Al}-\mathrm{Mg}-\mathrm{Si}$ alloys utilized in high-speed rail. In this work, the pitting corrosion of a nature-aged commercial 6005A-T6 aluminum extrusion profile for 200 days was studied comprehensively via the 
top-down engineering approach [29]. The shapes and the depths of the pits after constant immersion for 10 days in $3.5 \mathrm{wt} \% \mathrm{NaCl}$ were captured and measured by optical microscope $(\mathrm{OM})$, three-dimensional optical profilometry (OP), and scanning electron microscope (SEM), providing detailed quantification of uniform pitting corrosion. Quantitative measurements of the depth of the pits are discussed in detail, providing a benchmark to develop numerical models and reveal the fundamental mechanisms of pitting corrosion.

\section{Methodology}

\subsection{Materials and Sample Preparation}

In this work, a commercial 6005-T6 extrusion profile for the frames of high-speed trains was selected as a case study, and its composition is listed in Table 1. It was nature-aged for 200 days at room temperature before completing the following measurements/investigations. The tensile specimens were fabricated based on the standard of TB/T 3260.1-2011 [30]; their schematic images are presented in Figure 1a. In line with standard of JB/T 7901-1999 [31], these tensile specimens were polished on $\mathrm{SiC}$ papers with mesh number of $240,400,800$, and 1000 per square inch, followed by polishing with Buehler diamond paste (LIXIEYIQI, Zhejiang, China). Moreover, the pre-weighted tensile specimens endured a constant immersion, for $240 \mathrm{~h}$, in $3.5 \mathrm{wt} \% \mathrm{NaCl}$ aqueous solution at room temperature without adjusting the $\mathrm{pH}$ value, which has been a common approach for measuring pitting corrosion behavior [12,32] and meets the requirements of the recommended standard, JB/T7901-1999 [31]. The corrosion products were removed by rinsing in a solution consisting of $50 \mathrm{~mL}$ phosphoric acid, $20 \mathrm{~g}$ chromium trioxide, and $950 \mathrm{~mL}$ deionized water in an ultrasonic basin at a temperature range of 80-100 ${ }^{\circ} \mathrm{C}$ for $5-10 \mathrm{~min}$. If the surface was not clear enough, specimens were cleaned in $7 \% \mathrm{HNO}_{3}$ for about $10 \mathrm{~s}$ to remove any corrosion products [33,34].

Table 1. Chemical composition of the commercial 6005A-T6 alloy at manufacture (wt \%).

\begin{tabular}{lccccccccc}
\hline Elements & $\mathbf{S i}$ & $\mathbf{F e}$ & $\mathbf{C u}$ & $\mathbf{M n}$ & $\mathbf{M g}$ & $\mathrm{Cr}$ & $\mathrm{Zn}$ & $\mathrm{Ti}$ & $\mathrm{Al}$ \\
\hline Content & $0.5-0.9$ & $\leq 0.35$ & $\leq 0.30$ & $\leq 0.30$ & $0.40-0.7$ & $\leq 0.30$ & $\leq 0.20$ & $\leq 0.10$ & Bal. \\
\hline
\end{tabular}

Since the size of the extrusion profile utilized for a high-speed train is extremely large, the investigated regions were screened out through high-throughput eddy current measurements, as shown in Figure 1b. Here, the Sigma2008B eddy current conductivity meter (Ximen Tianyan Instrument Co., Ltd., Xiamen, China) was used, supporting the initial information of the structural heterogeneity. Subsequently, under the guidance of the recommended national standard (GB/T 3246.1-2000 [35]), the samples used for the microstructure characterizations were polished on $\mathrm{SiC}$ papers with mesh number of $80,240,400,800,1000,1500,2000,2500$, and 3000 per square inch, followed by polishing with Buehler diamond paste on a polishing cloth and subsequent electrochemical polishing. Finally, these specimens were rinsed with ethanol in an ultrasonic bath to remove any dust on the surface.

\subsection{Surface Characterization and Pit Depth}

Non-destructive OM measurements not only show the microstructures and morphologies of the surface but also provide a traditional approach for determining the pit depth after pitting corrosion. Here, the OLYMPUS GX51F optical microscope (Olympus Cop., Tokyo, Japan) and NPFLEX three-dimensional optical profilometry (Bruker NPFLEX, Tucson, AZ, USA) were utilized to present the pit depth, diameter, and volume for statistical analysis. In order to obtain precise data, the measurement of the pit depth must be carried out in triplicate (at least). Especially, when using the optical microscope to determine the pit depth under the recommended national standard, GB/T 18590-2001 [36], each pit is measured at four magnitudes of enlargement of $\times 100, \times 200, \times 500$, and $\times 1000$. Moreover, much more precise morphological parameters of a pit, including depth and volume, 
can be obtained by 3D optical profilometry with a depth resolution as high as $0.1 \mathrm{~nm}$. The scanning electron microscopy (ZEISS GemniSEM500, Oberkochen, Germany) was performed using a beam energy of $15 \mathrm{kV}$ to capture the secondary electron and backscattered electron images, thus revealing both the morphology and the compositions of the surface and precipitates/particles.
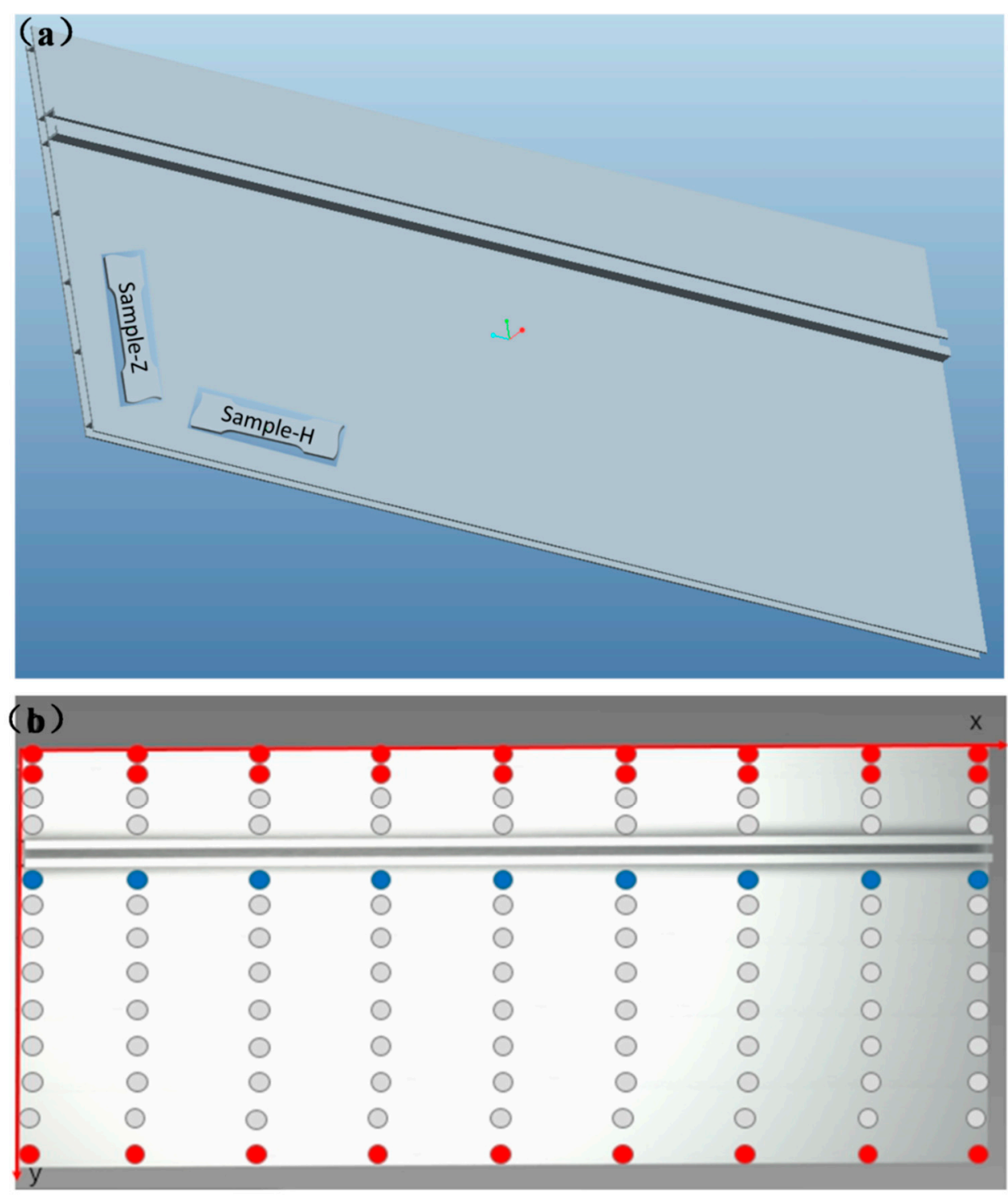

Figure 1. The schematic diagrams of the commercial 6005A-T6 extrusion profile for high-speed trains in different views: (a) 3D view and (b) top view. The fabricated tensile samples parallel and perpendicular to the extrusion direction are labeled by $\mathrm{H}$ and $\mathrm{Z}$, respectively. The red, navy, and gray points highlight the selected region with the maximum, the normal, and the minimum value of the eddy current, respectively.

\section{Results and Discussions}

To address the aforementioned challenge of screening out the investigated region in such a large extrusion profile shown in Figure 1, high-throughput eddy current measurements were performed to identify the structural heterogeneity and, thus, to fabricate the specimens. Figure $2 \mathrm{a}$ shows the linear contour plot of the eddy current of the naturally aged 6005A-T6 alloy. Based on the initial rough measurements, it was found that the microstructures along the $\mathrm{x}$-direction were homogeneous. On the contrary, the microstructures along the y-direction were heterogeneous, caused by the difference in the shapes and size of the extrusion profile shown in Figure 1a. This is the reason why the high-throughput 
measurements, with a step of $20 \mathrm{~cm}$ along the $\mathrm{x}$-direction and $\sim 5 \mathrm{~cm}$ along the $\mathrm{y}$-direction, were performed. It is also suggested that different microstructures could be conventionally captured if the specimens were manufactured along the y-direction, which is perpendicular to the extrusion direction. Accordingly, the screened-out microstructures with an eddy current of $25.58 \mathrm{MS} / \mathrm{m}, 26.24 \mathrm{MS} / \mathrm{m}$, and 28.10 MS $/ \mathrm{m}$, are presented in Figure $2 \mathrm{~b}-\mathrm{d}$. The groove position had the largest grain size while the edge part of the profile had the smallest grain size. Moreover, with a reduction in grain size, the eddy current enhanced. It is worth mentioning that these microstructures all endured a constant immersion for $240 \mathrm{~h}$ in $3.5 \mathrm{wt} \% \mathrm{NaCl}$ aqueous solution. The number of pits in the large grains was the highest while the number in the fine grains was the lowest, indicating that fine grains have the best corrosion resistance in the Al matrix. This is because there are more intermetallic particles in coarse grains, which are also bigger and have more continuous anodic and cathodic particles constituted by alloying elements [12].
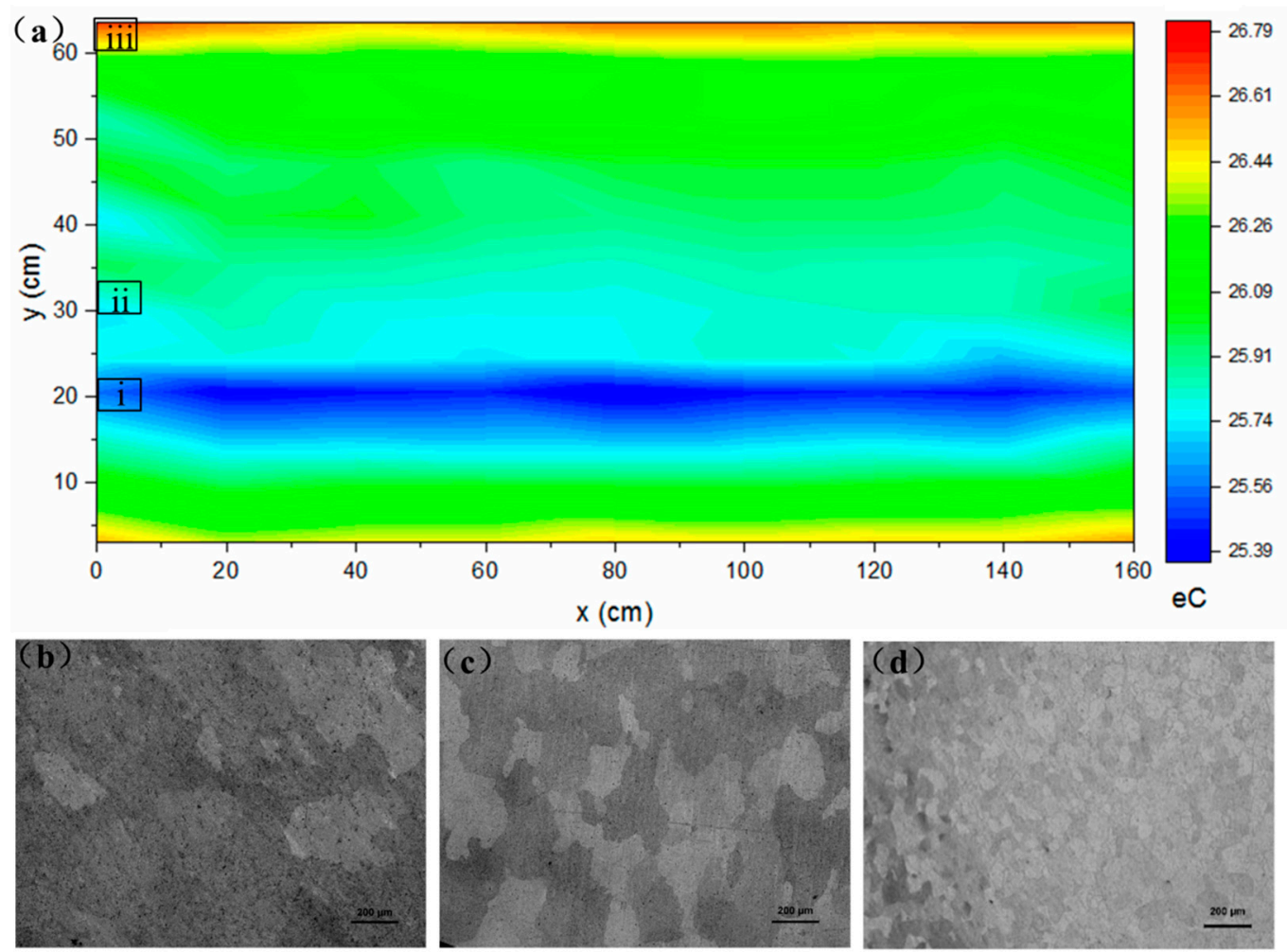

Figure 2. Eddy currents and classical optical microstructures of 6005A-T6 alloy. (a) The linear contour plot of the eddy current of the naturally aged 6005A-T6 alloy. (b-d) The screened-out microstructures with an eddy current of $25.58 \mathrm{MS} / \mathrm{m}, 26.24 \mathrm{MS} / \mathrm{m}$, and $28.10 \mathrm{MS} / \mathrm{m}$, which endured a constant immersion for $240 \mathrm{~h}$ in $3.5 \mathrm{wt} \% \mathrm{NaCl}$ and are labeled as i-iii in (a), respectively. The maximum and minimum values of the eddy current are set to $26.79 \mathrm{MS} / \mathrm{m}$ and $25.39 \mathrm{MS} / \mathrm{m}$ in the red-green-blue (RGB) color scale in order to present the various zones clearly. The rectangles in (a) schematically highlight the positions of these three samples in (b-d), respectively.

Figures 3 and 4 display the classical morphologies of the pits of Sample-H and Sample-Z after constant immersion, respectively. It is well known that the classical morphologies of precipitates of $6 \mathrm{XXX}$ alloys are the plate-like $\beta-\mathrm{Al}_{5} \mathrm{FeSi}$ and the rounded $\alpha-\mathrm{Al}_{12}(\mathrm{Fe}, \mathrm{Mn})_{3} \mathrm{Si}$ particles ranging between 1 and $10 \mathrm{um}$ [37]. The needle-like $\beta^{\prime \prime}$ phase, which is normally identified as $\mathrm{Mg}_{5} \mathrm{Si}_{6}$, has been considered to be the most effective strengthening precipitate among all kinds of precipitates in 6XXX alloys [5]. The evolution of the intermetallic structures of $\beta-\mathrm{Al}_{5} \mathrm{FeSi}$ and $\alpha-\mathrm{Al}_{12}(\mathrm{Fe}, \mathrm{Mn})_{3} \mathrm{Si}$ have been captured in $3 \mathrm{D}$, revealing qualitative and quantitative analysis of the reconstructed morphology of the metallic microstructures of 6005A alloy, especially the connectivity/distribution of those 
intermetallics [38]. Based on the morphologies of those pits, it is revealing that the precipitates play an extremely important role in pitting corrosion by acting either as a cathode or anode resulting in the dissolution of themselves or the $\mathrm{Al}$ matrix, shown in Figures 3 and 4. The typical features of pitting corrosion include: (i) peripheral dissolution/trenching of the Al matrix around the small size cathodic precipitates, (ii) channeling corrosion, (iii) intergranular attack initiating the pitting, and (iv) large pits in the grains. As shown in Figure 5, several large corrosion pits in Figure 3 were chosen and enlarged at different magnitudes, revealing that the front of the corrosion pathways were dominated by grain boundaries due to intergranular corrosion and indicating the initiation of cracks within the pit-to-crack transformation scheme.

Table 2. Depth of pits measured by optical microscope.

\begin{tabular}{|c|c|c|c|c|c|c|}
\hline \multirow{2}{*}{ Sample } & \multirow{2}{*}{ Pit No. } & \multicolumn{4}{|c|}{ The Depth of Pit at Magnitudes of Enlargement } & \multirow{2}{*}{$\begin{array}{l}\text { Averaged Depth } \\
(\mu \mathrm{m})\end{array}$} \\
\hline & & $\times 1000$ & $\times 500$ & $\times 200$ & $\times 100$ & \\
\hline \multirow{13}{*}{ Sample-H } & A & & 18 & 20 & 17 & 18.3 \\
\hline & B & 6 & 5 & 5 & & 5.3 \\
\hline & $\mathrm{C}$ & 3 & 3 & 5 & & 3.7 \\
\hline & $\mathrm{D}$ & 4 & 4 & 4 & & 4.0 \\
\hline & $\mathrm{E}$ & 17 & 12 & 12 & & 13.7 \\
\hline & $\mathrm{F}$ & & 69 & 72 & 70 & 70.3 \\
\hline & G & & 39 & 41 & 40 & 40.0 \\
\hline & $\mathrm{H}$ & & 79 & 80 & 80 & 79.7 \\
\hline & I & 9 & 11 & 10 & & 10.0 \\
\hline & $\mathrm{J}$ & 9 & 8 & 9 & & 8.7 \\
\hline & $\mathrm{K}$ & 10 & 8 & 12 & & 10.0 \\
\hline & $\mathrm{L}$ & 12 & 11 & 12 & & 11.7 \\
\hline & $\mathrm{M}$ & 6 & 6 & 6 & & 6.0 \\
\hline \multirow{12}{*}{ Sample-Z } & A & 4 & 5 & 5 & & 4.7 \\
\hline & B & 8 & 9 & 9 & & 8.7 \\
\hline & $C$ & 13 & 10 & 12 & & 11.7 \\
\hline & $\mathrm{D}$ & 9 & 8 & 7 & & 8.0 \\
\hline & $\mathrm{E}$ & 6 & 6 & 6 & & 6.0 \\
\hline & $F$ & 4 & 4 & 5 & & 4.3 \\
\hline & G & & 4 & 4 & 4 & 4.0 \\
\hline & $\mathrm{H}$ & & 31 & 30 & 30 & 30.3 \\
\hline & I & & 12 & 13 & 12 & 12.3 \\
\hline & $\mathrm{J}$ & 12 & 11 & 11 & & 11.3 \\
\hline & $\mathrm{K}$ & 2 & 2 & 2 & & 2.0 \\
\hline & $\mathrm{L}$ & 6 & 5 & 7 & & 6.0 \\
\hline
\end{tabular}

Moreover, it is worth mentioning that the polishing pit should be avoided in the measurement of pit depth, because its morphology is different to the etching one in size and depth. In particular, the depth of the etching pit is measured at three magnitudes of enlargement under the guidance of the recommended national standard GB/T 18590-2001 [36]. The strategy for selecting these magnitudes of enlargement is dominated by the volume and depth of the pits. In general, the larger the pit, the smaller the magnitude of enlargement $(\times 100)$. As listed in Table 2, the depths of each point shown in Figures 3 and 4 are summarized. For large pits, it is not necessary to measure the pit depth via the highest 
magnitude of enlargement $(\times 1000)$. For a small pit, the lowest magnitude of enlargement $(\times 100)$ should be avoided. After measuring each pit depth three times, the average value can be estimated for each pit. The corrosion pits with a depth about $10 \mu \mathrm{m}$ have the most uniform morphology for those selected regions together with the deepest ones of $79.7 \mu \mathrm{m}$ and $30.3 \mu \mathrm{m}$ on the sample fabricated parallel and perpendicular to the extrusion's direction, respectively. Similarly, the unique depth of the corrosion pit of 7075-T6 alloy was $94 \mu \mathrm{m}$ after a constant immersion in $\mathrm{NaCl}$ for 30 days at $\mathrm{pH}$ 5 and $20{ }^{\circ} \mathrm{C}$ [32]. Since the pit depth will increase with immersion time [34], it is critical to set up a corresponding database for the further modeling of pit depth and the accuracy of the predicted results, such as the evolution of pit depth, which is critically important to the damage tolerance of the materials.
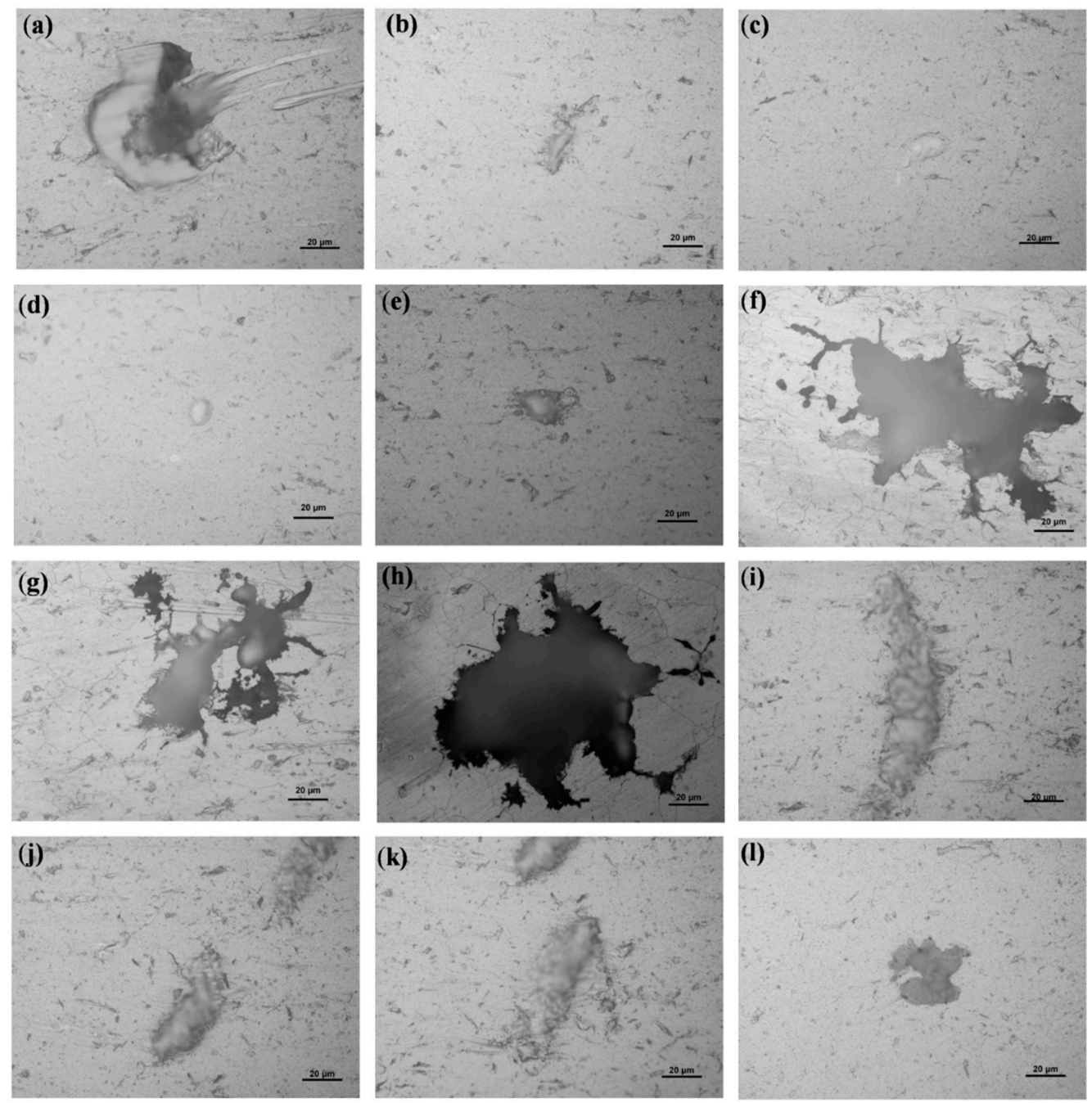

Figure 3. Optical morphologies of pits observed on Sample-H after constant immersion. (a-1) are the selected pitting points from A to K listed in Table 2, respectively.

Besides the surface morphology, three-dimensional optical profilometry is usually used to analyze the number, size, and depth of pits after a constant immersion test [32,34]. Figures 6 and 7 present the qualitative and quantitative descriptions of the pits of Sample-H and Sample- $\mathrm{Z}$, respectively. Due to the different heights among the pits, precipitates, and the matrix, the samples are characterized clearly by the gradient colors scaled depths. In particular, the black circles in Figure 6a, Figure 7a highlight the aforementioned peripheral dissolution/trenching of the $\mathrm{Al}$ matrix around the small cathodic precipitates. These narrow blue stripes, highlighted by rectangles, show classical channeling 
corrosion, which also merges some of the pits. In those selected regions, the depths of the coarse pits can be measured accurately, shown as linear profiles in Figures 6 and 7.
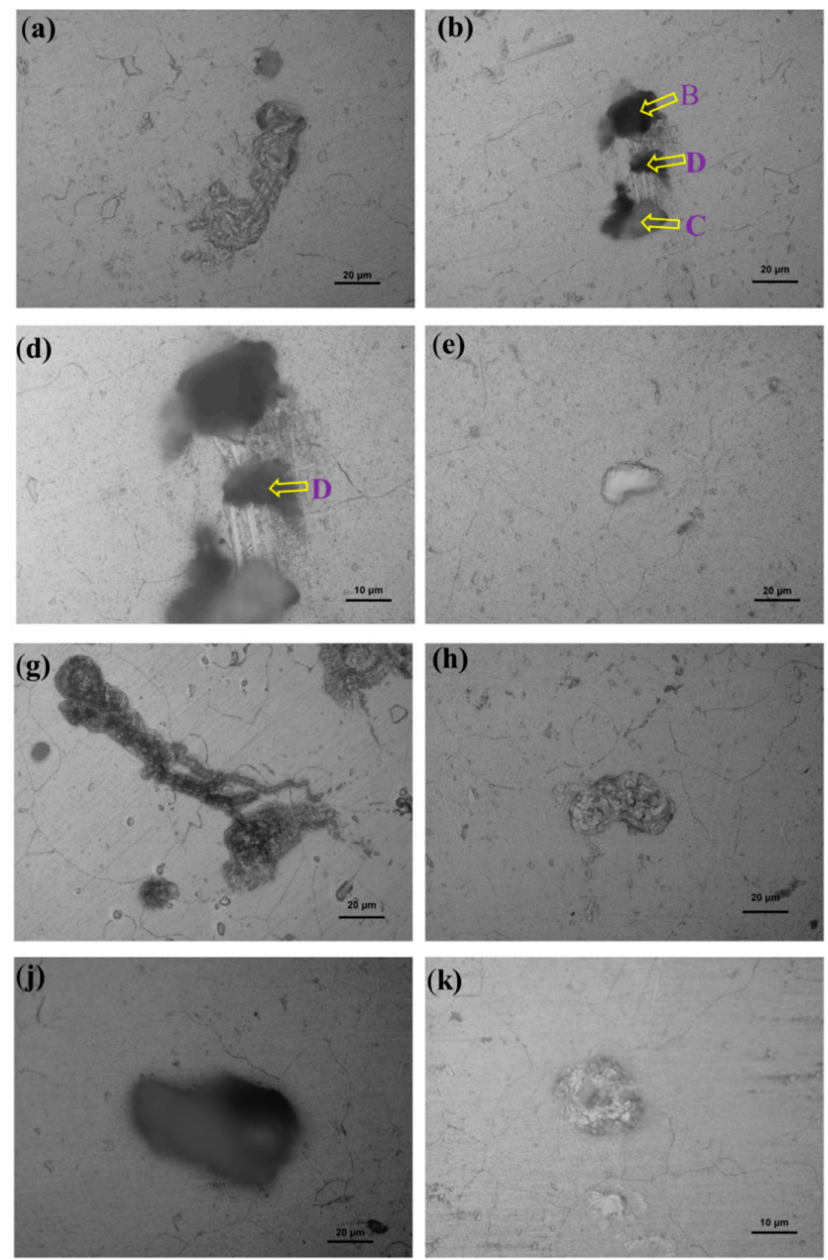
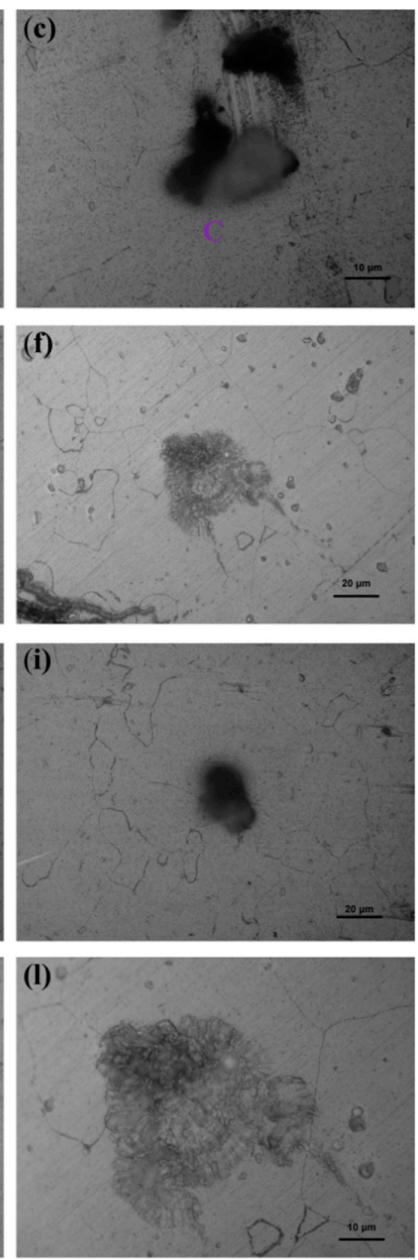

Figure 4. Optical morphologies of pits observed on Sample-Z after constant immersion: (a-k) are the selected pitting points from A to K listed in Table 2, and (1) is the amplified region of (f), highlighting the caved grains along the grain boundaries.

Figure 8 presents the SEM images of the surface of the 6005A-T6 alloy after constant immersion for $240 \mathrm{~h}$ in $3.5 \mathrm{wt} \% \mathrm{NaCl}$. Three typical structures, including the morphology of the pits, the etched grain boundaries enriched with pits, and the corrosion product, are displayed in Figure 8a-c, respectively. The morphologies of the pits are typically dominated by the distribution of precipitates, such as the highlighted zones in Figure 6a, Figure 7a. Based on the Energy Dispersive Spectrometer (EDS) analysis of the composition of the particle shown in Figure 8c,d, it can be seen that the corrosion product is enriched with $\mathrm{Al}, \mathrm{Si}, \mathrm{O}$, and $\mathrm{Fe}$. It is worth mentioning that solute clustering and precipitates during natural aging play key roles not only in solid-solution strengthening but also in pitting corrosion.

On one hand, the developed heterogeneous structures constructed by a series of hardening precipitates and solute clusters result in precipitation strengthening and solid-solution strengthening mechanisms [1,33,39]. For example, the purpose of the T6 treatment (or peak aging) of the 6005A-T6 alloy is to obtain a high number density of precipitates, giving maximum strength, and it is commonly utilized in the processing of high-strength $\mathrm{Al}$ alloys [1]. Moreover, the heterogeneous solute distribution has a strong effect on the dislocation motion (i.e., pinning effect), thus, strengthening the materials.

On the other hand, heterogeneous structures constituted of a series of hardening precipitates and solute clusters will initiate localized corrosion at the secondary phases or their surrounding $\mathrm{Al}$ matrix, which will form pits and begin the degradation of the mechanical properties of the alloy. 
In general, solute clustering during natural aging is mainly dominated by frozen-in excess vacancies, which could be suppressed by a short-term interruption of the quenching process [40]. Precipitates usually have a composition different from that of the matrix, yielding a local chemistry change [1]. The corresponding electrochemical properties, including pitting corrosion and stress corrosion cracking, are detrimentally affected by precipitate-free zones [1]. Typically, iron-rich particles have higher cathodic activities than pure $\mathrm{Al}$, meaning that pitting initiations prevail at cathodic ( $\mathrm{Cu}$ - or Fe-rich) particles in chloride containing neutral aerated solution [12,41]. Oxygen reduction is the dominant reaction and is conventionally carried out on these precipitate particles [12,41,42]. This is the reason why our captured corrosion product is enriched in $\mathrm{Al}, \mathrm{Si}, \mathrm{O}$, and $\mathrm{Fe}$, as presented in Figure 8d. Moreover, the morphology of the $\mathrm{Al}(\mathrm{Fe}, \mathrm{Cr}) \mathrm{Si}$ particles of $6005 \mathrm{~A}$ alloy could be optimized from granular to rod by increasing the aging temperature or aging time, which could also be segregated at the grain boundaries [43]. Therefore, through combining the information from Figure $8 \mathrm{~d}$, it is understood that the arrows in Figure 5 indicate that the segregation of $\mathrm{Fe}$ and $\mathrm{Si}$ and the precipitation of $\mathrm{Al}(\mathrm{Fe}, \mathrm{Cr}) \mathrm{Si}$ particles contribute to the aforementioned intergranular attack, initiating the pitting.
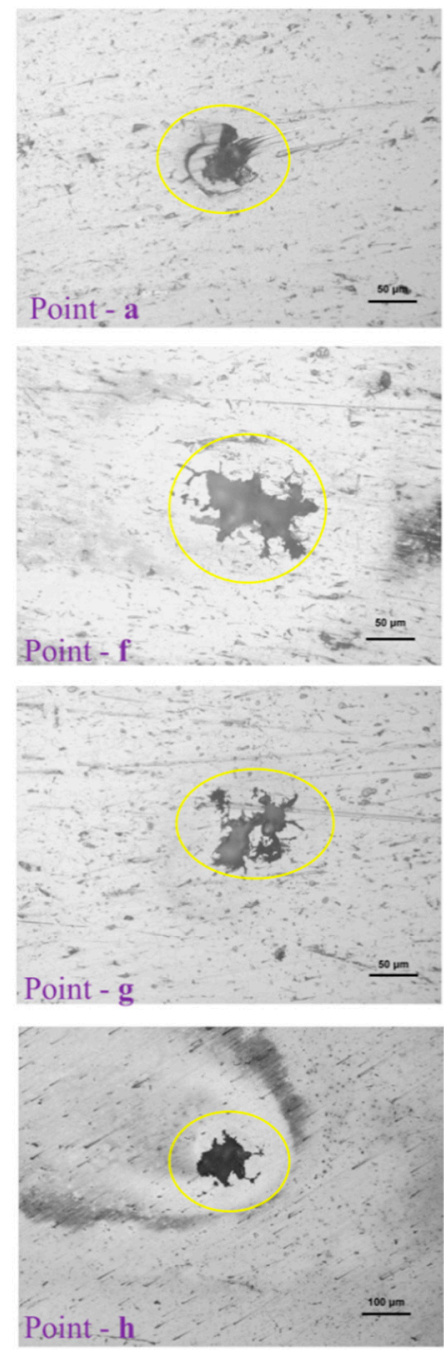

$\times 100$
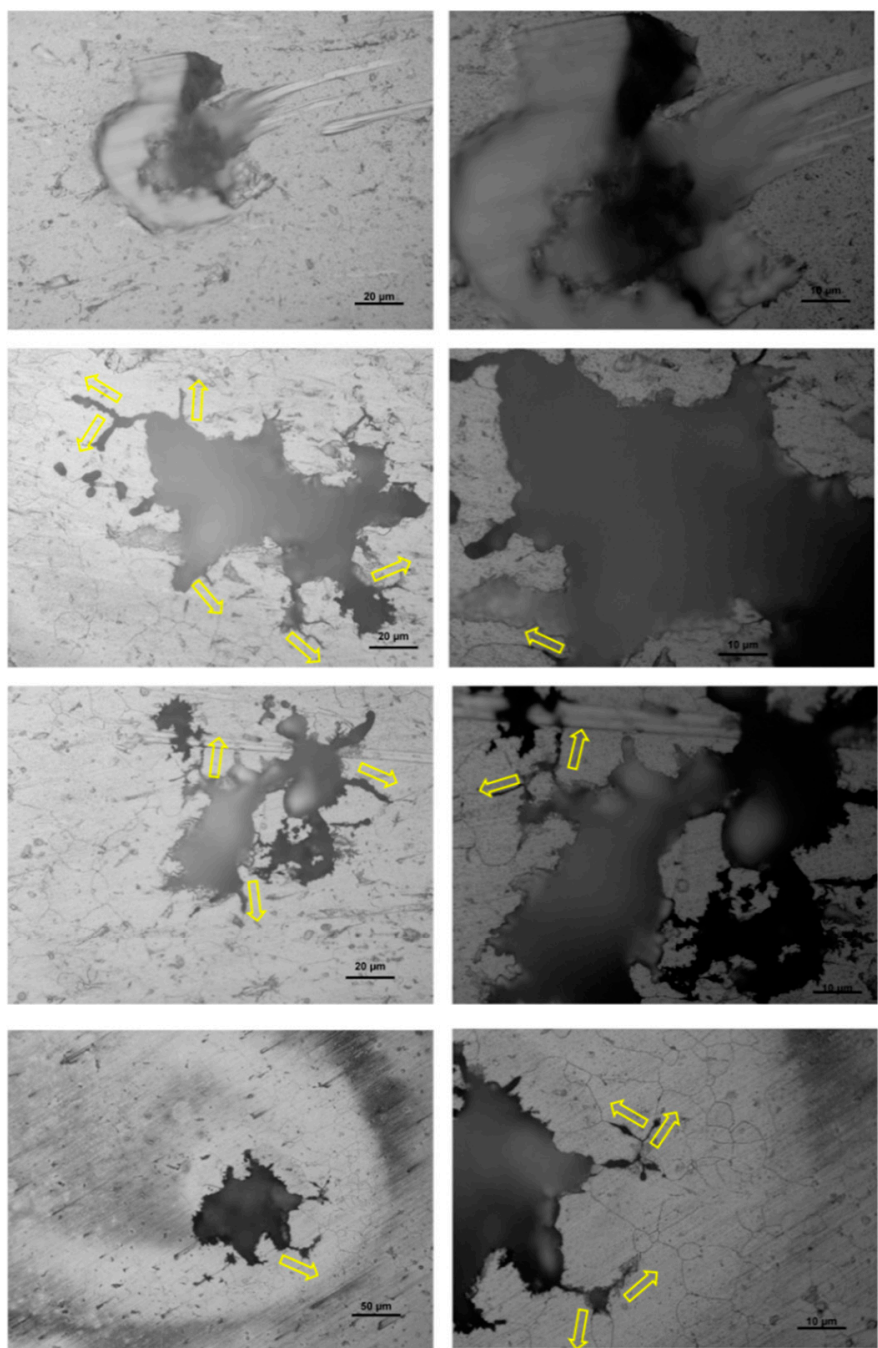

$\times 200$

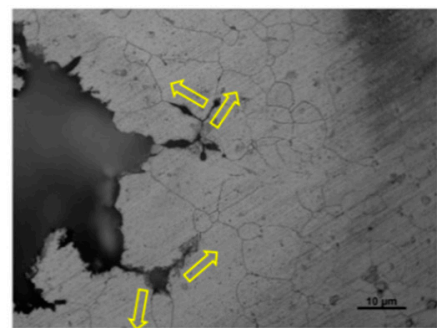

$\times 1000$

Figure 5. Morphologies of classical pits at various magnitudes of enlargement during measuring of their depths, the data of which are listed in Table 2. The yellow arrows highlight the initiation of cracks within the pit-to-crack transformation scheme. 

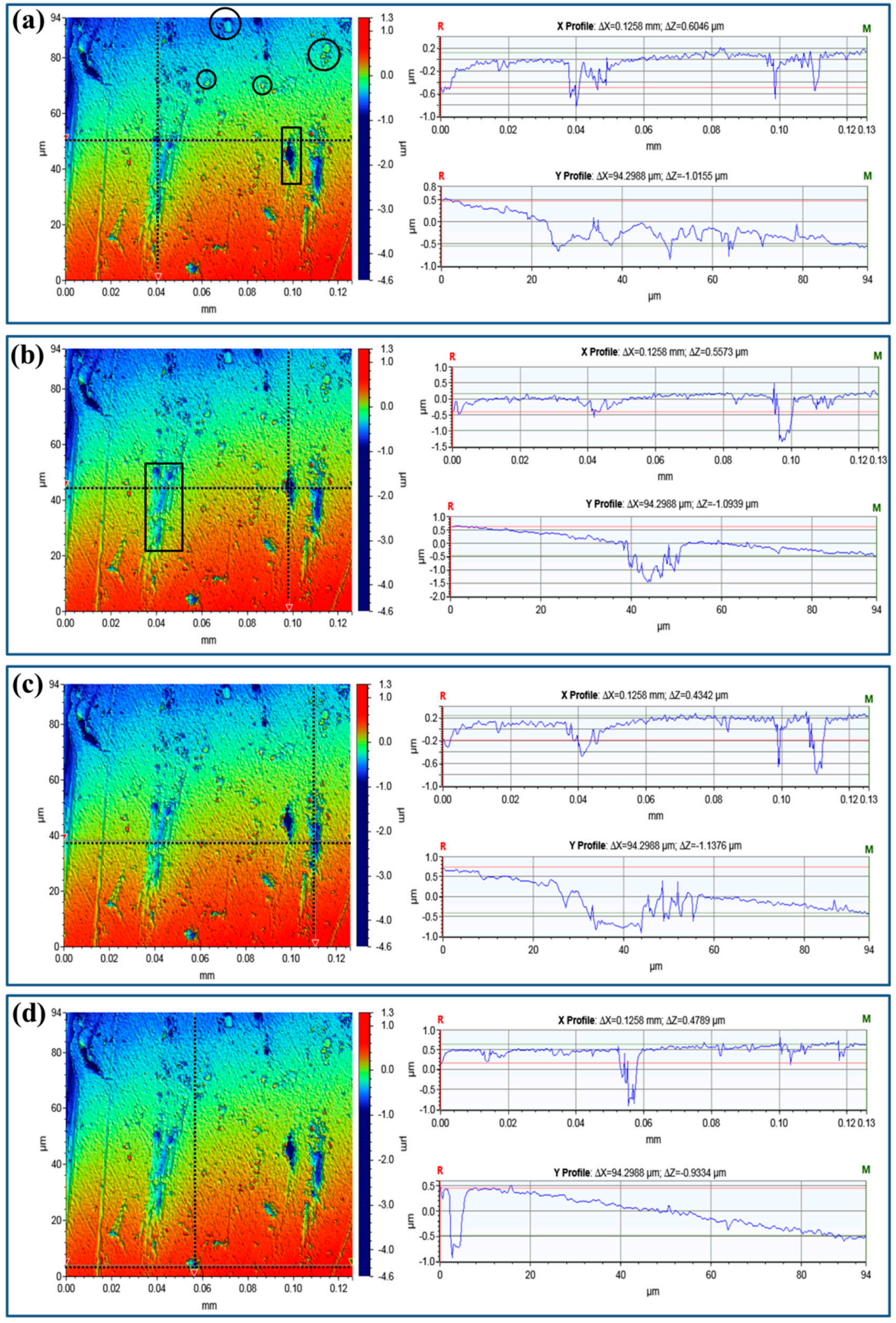

Figure 6. Three-dimensional optical profilometry images of Sample-H after constant immersion for $240 \mathrm{~h}$ in $3.5 \mathrm{wt} \% \mathrm{NaCl}$ together with the line profiles of the pits. The black circles highlight the peripheral dissolution/trenching of the $\mathrm{Al}$ matrix around the cathodic precipitates, while rectangles show the classical channeling corrosion merging pits. (a-d) highlight the line profiles crossing the selected pit, which are identified these black dot lines. 

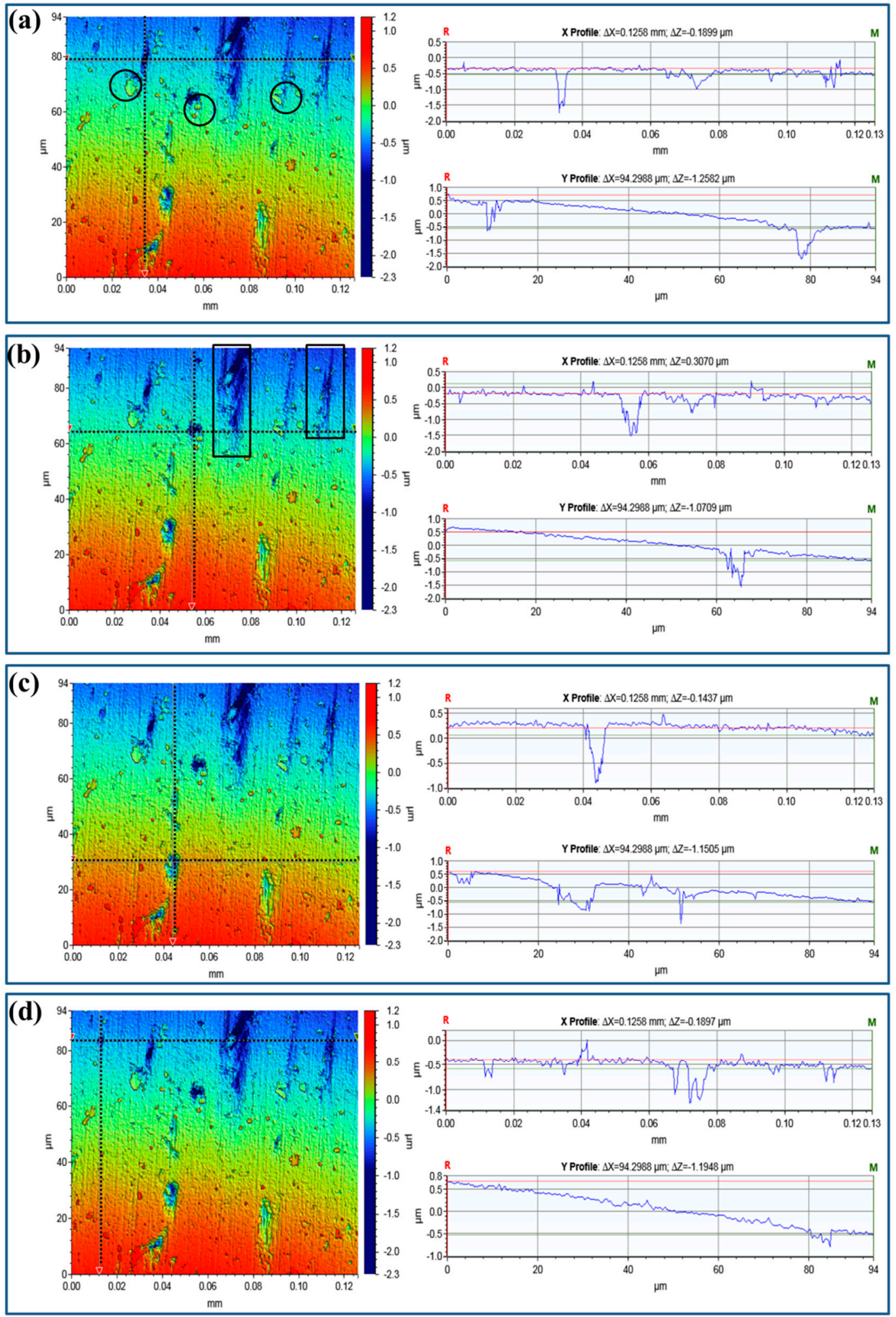

Figure 7. Three-dimensional optical profilometry images of Sample-Z after constant immersion for $240 \mathrm{~h}$ in $3.5 \mathrm{wt} \% \mathrm{NaCl}$ together with the line profiles of the measured pits. (a-d) highlight the line profiles crossing the selected pit, which are identified these black dot lines. 

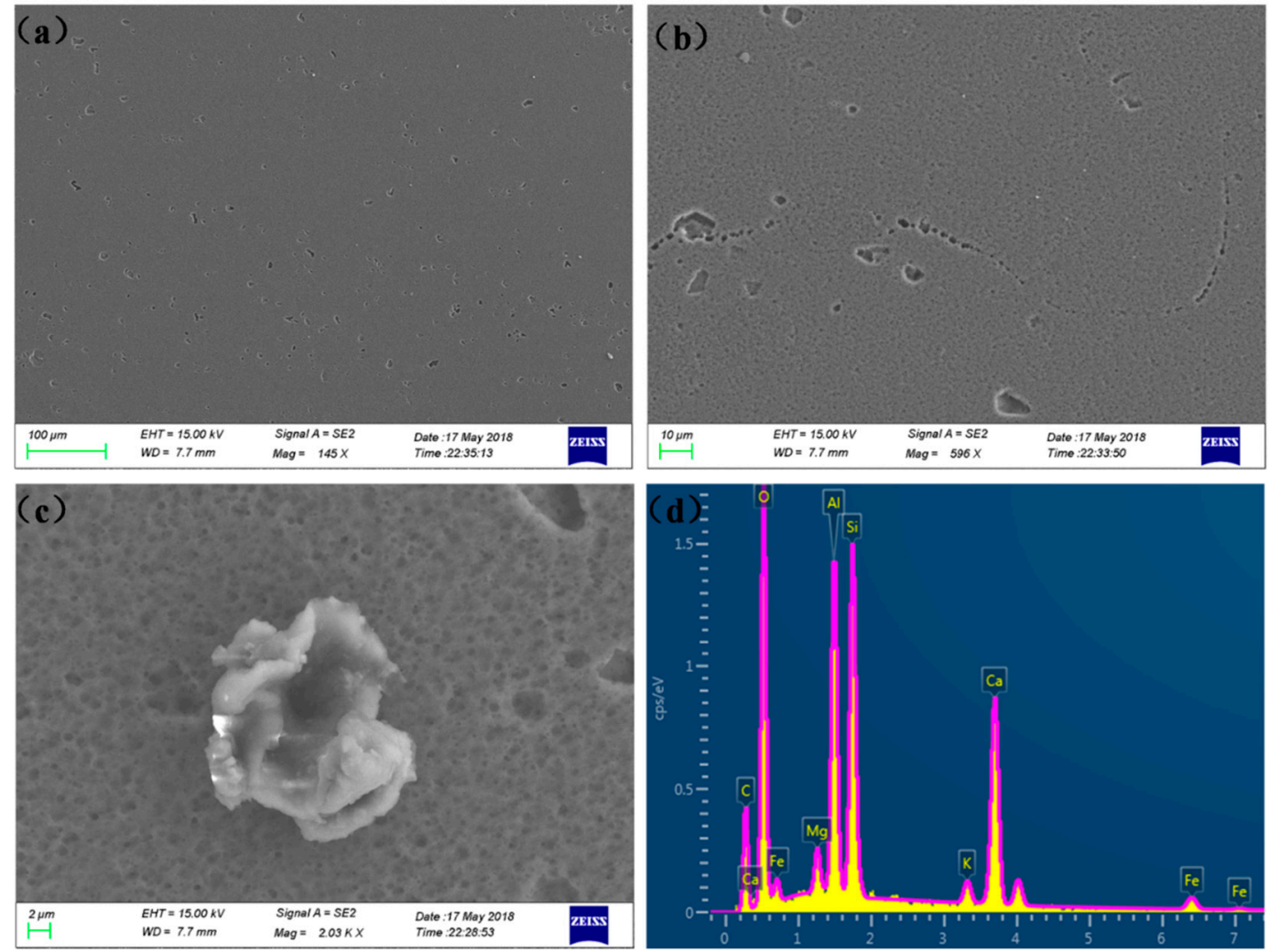

Figure 8. SEM images of the surface of 6005A-T6 alloy after constant immersion for $240 \mathrm{~h}$ in $3.5 \mathrm{wt} \%$ $\mathrm{NaCl}$ : (a) the morphology of the pits, (b) the etched grain boundaries enriched with pits, and (c,d) the morphology of the bright particle together with its EDS analysis.

Motivated by the management/maintenance of the China Railway High-speed series in environmental conditions, it is expected that more efforts will be performed to estimate pitting damage initiation and propagation, to set up a corresponding database, and to develop advanced processing strategies, which will support the foundations for interactive corrosion risk management. The measured pit depth would not only help to understand the effective thickness/cross-section area of the specimens but also to create models that predict the remaining stress and to manage the damage tolerance of the materials. For example, it has been proposed that the typical stress reduction for the pre-corroded tensile specimens at different immersion times can be expressed as $\Delta \sigma=\sigma_{0}-\sigma_{j}$ [44]. The ratio of remaining stress $\left(\sigma_{j}\right)$ to benchmark stress $\left(\sigma_{0}\right)$ is assumed to be equivalent to the ratio of remaining undamaged cross-section area $\left(A_{j}\right)$ to original section area $\left(A_{0}\right)[44,45]$. Moreover, based on the well-known negative natural aging (NA) effect, it has been found that hardness recovery in the nugget zone and the thermo-mechanically affected zone of 6005A-T6 alloy have been observed during post-weld NA, which attributes to the formation of clusters at an early stage and GP-zone precipitation after 4 weeks of NA [46]. Large and deep pits are replaced with small and shallow ones after equal-channel angular pressing in 6061 alloy, which leads to a substantial increase in the dislocation density, re-distribution of precipitates, crystallite refinement, alteration of the surface area of cathodic sites, and increase in the volume fraction of grain boundaries that affects corrosion resistance [47]. In order to support the foundations for the interactive corrosion risk management of equipment/infrastructure, such as the aforementioned trains in environmental conditions, more efforts are required to estimate pitting damage initiation and accumulation, set up the corresponding database, and develop advanced processing strategies. 


\section{Conclusions}

In this work, the pitting corrosion of a nature-aged commercial 6005A-T6 aluminum extrusion profile for 200 days was studied comprehensively. To address the challenge of screening out the investigated region in such a large extrusion profile, high-throughput eddy current measurements were performed to identify the aforementioned structural heterogeneity, in order to fabricate the specimens. After constant immersion for $240 \mathrm{~h}$ in $3.5 \mathrm{wt} \% \mathrm{NaCl}$, it was found that the traditional features of pitting corrosion include: (i) peripheral dissolution/trenching of the $\mathrm{Al}$ matrix around the small size cathodic precipitates, (ii) channeling corrosion, (iii) intergranular attack initiating the pitting, and (iv) large pits in the grains. Due to the high density of continuous anodic and cathodic particles constituted by alloying elements in coarse grains, the number of pits in the coarse grains was the highest while the number in the fine grains was the lowest, indicating that fine grains have the best corrosion resistance. The experimental dataset of pit depth integrated with the corresponding microstructures would set the benchmarks for further modeling of pit depth and the accuracy of the predicted results, such as the evolution of the pit depth and the remaining ductility, in order to manage the damage tolerance of the materials.

Author Contributions: Conceptualization, W.Y.W., Q.G., J.S., J.G. (Jun Gao) and J.M.; methodology, J.G. (Junfeng Gao), C.Z. and J.T.; validation, J.G. (Junfeng Gao), C.Z. and J.T.; formal analysis, Q.G., J.S. and W.Y.W.; investigation, J.G. (Junfeng Gao), C.Z., J.T., Q.G., J.S. and W.Y.W.; data curation, Q.G., J.S., W.Y.W. and J.G. (Jun Gao); writing-original draft preparation, Q.G., J.S., W.Y.W., J.W., B.T., H.K., H.W., J.H. and J.G. (Jun Gao); writing-review and editing, Q.G., J.S., W.Y.W., J.W., B.T., H.K., J.Y.H., J.G. (Jun Gao), J.M. and J.L.; visualization, Q.G., J.S., and W.Y.W.; supervision, W.Y.W., J.M. and J.L.; project administration, W.Y.W., J.G. (Jun Gao), J.M. and J.L.; funding acquisition, W.Y.W., J.G. (Jun Gao), J.M. and J.L.

Funding: This work was financially supported by the National Natural Science Foundation of China (51690163) and CRRC Tangshan Co., LTD (Contract No. 201750463031).

Conflicts of Interest: The authors declare no conflict of interest.

\section{References}

1. Sun, W.; Zhu, Y.; Marceau, R.; Wang, L.; Zhang, Q.; Gao, X.; Hutchinson, C. Precipitation strengthening of aluminum alloys by room-temperature cyclic plasticity. Science 2019, 363, 972-975. [CrossRef]

2. Werinos, M.; Antrekowitsch, H.; Ebner, T.; Prillhofer, R.; Curtin, W.A.; Uggowitzer, P.J; Pogatscher, S. Design strategy for controlled natural aging in Al-Mg-Si alloys. Acta Mater. 2016, 118, 296-305. [CrossRef]

3. Martinsen, F.A.; Ehlers, F.J.H.; Torsæter, M.; Holmestad, R. Reversal of the negative natural aging effect in Al-Mg-Si alloys. Acta Mater. 2012, 60, 6091-6101. [CrossRef]

4. Nandy, S.; Bakkar, M.A.; Das, D. Influence of Ageing on Mechanical Properties of 6063 Al Alloy. Mater. Today Proc. 2015, 2, 1234-1242. [CrossRef]

5. Liu, C.H.; Lai, Y.X.; Chen, J.H.; Tao, G.H.; Liu, L.M.; Ma, P.P.; Wu, C.L. Natural-aging-induced reversal of the precipitation pathways in an Al-Mg-Si alloy. Scripta Mater. 2016, 115, 150-154. [CrossRef]

6. Jin, S.; Ngai, T.; Li, L.; Lai, Y.; Chen, Z.; Wang, A. Influence of natural aging and pre-treatment on the precipitation and age-hardening behavior of Al-1.0Mg-0.65Si-0.24Cu alloy. J. Alloy. Compd. 2018, 742, 852-859. [CrossRef]

7. Ding, L.; Jia, Z.; Zhang, Z.; Sanders, R.E.; Liu, Q.; Yang, G. The natural aging and precipitation hardening behaviour of Al-Mg-Si-Cu alloys with different $\mathrm{Mg} / \mathrm{Si}$ ratios and $\mathrm{Cu}$ additions. Mater. Sci. Eng. A 2015, 627, 119-126. [CrossRef]

8. Marquis, E.A.; Hyde, J.M. Applications of atom-probe tomography to the characterisation of solute behaviours. Mater. Sci. Eng. R 2010, 69, 37-62. [CrossRef]

9. Marioara, C.D.; Andersen, S.J; Stene, T.N.; Hasting, H.; Walmsley, J.; Van Helvoort, A.T.J; Holmestad, R. The effect of $\mathrm{Cu}$ on precipitation in Al-Mg-Si alloys. Philos. Mag. 2007, 87, 3385-3413. [CrossRef]

10. Man, J.; Jing, L.; Jie, S.G. The effects of $\mathrm{Cu}$ addition on the microstructure and thermal stability of an Al-Mg-Si alloy. J. Alloy. Compd. 2007, 437, 146-150. [CrossRef]

11. Aruga, Y.; Kozuka, M.; Takaki, Y.; Sato, T. Effects of natural aging after pre-aging on clustering and bake-hardening behavior in an Al-Mg-Si alloy. Scripta Mater. 2016, 116, 82-86. [CrossRef] 
12. Tian, W.; Li, S.; Wang, B.; Liu, J.; Yu, M. Pitting corrosion of naturally aged AA 7075 aluminum alloys with bimodal grain size. Corros. Sci. 2016, 113, 1-16. [CrossRef]

13. Wang, J.; Zhang, B.; Zhou, Y.T.; Ma, X.L. Multiple twins of a decagonal approximant embedded in $\mathrm{S}^{-\mathrm{Al}_{2} \mathrm{CuMg}}$ phase resulting in pitting initiation of a 2024Al alloy. Acta Mater. 2015, 82, 22-31. [CrossRef]

14. Wang, J.; Zhang, B.; Wu, B.; Ma, X.L. Size-dependent role of S phase in pitting initiation of 2024Al alloy. Corros. Sci. 2016, 105, 183-189. [CrossRef]

15. Starke, E.A.; Staley, J.T. Application of modern aluminum alloys to aircraft. Prog. Aerosp. Sci. 1996, 32, 131-172. [CrossRef]

16. Donatus, U.; Thompson, G.E.; Omotoyinbo, J.A.; Alaneme, K.K.; Aribo, S.; Agbabiaka, O.G. Corrosion pathways in aluminium alloys. Trans. Nonferrous. Met. Soc. China 2017, 27, 55-62. [CrossRef]

17. Stannard, T.J.; Williams, J.J.; Singh, S.S.; Sundaram Singaravelu, A.S.; Xiao, X.; Chawla, N. 3D time-resolved observations of corrosion and corrosion-fatigue crack initiation and growth in peak-aged $\mathrm{Al} 7075$ using synchrotron X-ray tomography. Corros. Sci. 2018, 138, 340-352. [CrossRef]

18. Ansari, T.Q.; Xiao, Z.; Hu, S.; Li, Y.; Luo, J.-L.; Shi, S.-Q. Phase-field model of pitting corrosion kinetics in metallic materials. npj Comput. Mater. 2018, 4, 38. [CrossRef]

19. Turnbull, A.; Wright, L.; Crocker, L. New insight into the pit-to-crack transition from finite element analysis of the stress and strain distribution around a corrosion pit. Corros. Sci. 2010, 52, 1492-1498. [CrossRef]

20. Turnbull, A.; Horner, D.A.; Connolly, B.J. Challenges in modelling the evolution of stress corrosion cracks from pits. Eng. Fract. Mech. 2009, 76, 633-640. [CrossRef]

21. Ralston, K.D.; Birbilis, N.; Cavanaugh, M.K.; Weyland, M.; Muddle, B.C.; Marceau, R.K.W. Role of nanostructure in pitting of Al-Cu-Mg alloys. Electrochimica Acta 2010, 55, 7834-7842. [CrossRef]

22. Wang, H.; Han, E.-H. Computational simulation of corrosion pit interactions under mechanochemical effects using a cellular automaton/finite element model. Corros. Sci. 2016, 103, 305-311. [CrossRef]

23. Soltis, J. Passivity breakdown, pit initiation and propagation of pits in metallic materials-Review. Corros. Sci. 2015, 90, 5-22. [CrossRef]

24. McCallum, K.; Zhao, J.; Workman, M.; Iannuzzi, M.; Kappes, M.; Payer, J.; Clemons, C.B.; Chawla, S.; Kreider, K.I.; Mimoto, N.; et al. Localized Corrosion Risk Assessment Using Markov Analysis. Corrosion 2014, 70, 1114-1127. [CrossRef]

25. $\mathrm{Li}, \mathrm{Y}$; $\mathrm{Xu}$, J. Role of late transition metals on pitting resistance of $\mathrm{Zr}-\mathrm{Ti}-(\mathrm{Cu}, \mathrm{Ni}, \mathrm{Co})-\mathrm{Al}$ bulk metallic glasses in $0.6 \mathrm{M} \mathrm{NaCl}$ aqueous solution. J. Mater. Sci. Technol. 2017, 33, 1278-1288. [CrossRef]

26. Liu, L.; Li, Y.; Wang, F. Electrochemical Corrosion Behavior of Nanocrystalline Materials-A Review. J. Mater. Sci. Technol. 2010, 26, 1-14. [CrossRef]

27. Ma, H.; Chen, X.-Q.; Li, R.; Wang, S.; Dong, J.; Ke, W. First-principles modeling of anisotropic anodic dissolution of metals and alloys in corrosive environments. Acta Materialia 2017, 130, 137-146. [CrossRef]

28. Wu, X.Y.; Niu, F.J.; Lin, Z.J.; Luo, J.; Zheng, H.; Shao, Z.J. Delamination frost heave in embankment of high speed railway in high altitude and seasonal frozen region. Cold Reg. Sci. Technol. 2018, 153, 25-32. [CrossRef]

29. Liu, Z.-K.; McDowell, D.L. The Penn State-Georgia Tech CCMD: ushering in the ICME Era. Int. Mater. Manuf. Innovat. 2014, 3, 28. [CrossRef]

30. TB/T 3260.1-2011. Aluminium and Aluminium Alloys Used on EMU. Part 1: Basic Requirement; CSR Qishuyan Locomotive \& Rolling Stock Technology Research Institute Co., Ltd.: Dalian, China, 2011.

31. JB/T 7901-1999. Metals Materials-Uniform Corrosion-Methods of Laboratory Immersion Testing; Ministry of Machine-Building Industry: Beijing, China, 1999.

32. Huang, I.W.; Hurley, B.L.; Yang, F.; Buchheit, R.G. Dependence on Temperature, $\mathrm{pH}$, and $\mathrm{Cl}^{-}$in the Uniform Corrosion of Aluminum Alloys 2024-T3, 6061-T6, and 7075-T6. Electrochimica Acta 2016, 199, $242-253$. [CrossRef]

33. Gupta, R.K.; Sukiman, N.L.; Cavanaugh, M.K.; Hinton, B.R.W.; Hutchinson, C.R.; Birbilis, N. Metastable pitting characteristics of aluminium alloys measured using current transients during potentiostatic polarisation. Electrochimica Acta 2012, 66, 245-254. [CrossRef]

34. Gupta, R.K.; Hinton, B.R.W.; Birbilis, N. The effect of chromate on the pitting susceptibility of AA7075-T651 studied using potentiostatic transients. Corros. Sci. 2014, 82, 197-207. [CrossRef]

35. GB/T 3246.1-2000. Wrough Aluminium and Aluminium Alloys Products Inspection Method for Structure; China Non-ferrous metals industry standard Institute of Metrology and Quality: Beijing, China, 2000. 
36. GB/T 18590-2001. Corrosion of Metals and Alloys-Evaluation of Pitting Corrosion; General Administration of Quality Supervision, Inspection and Quarantine: Beijing, China, 2001.

37. Lassance, D.; Fabregue, D.; Delannay, F.; Pardoen, T. Micromechanics of room and high temperature fracture in 6xxx Al alloys. Prog. Mater. Sci. 2007, 52, 62-129. [CrossRef]

38. Kuijpers, N.C.W.; Tirel, J.; Hanlon, D.N.; van der Zwaag, S. Quantification of the evolution of the 3D intermetallic structure in a 6005A aluminium alloy during a homogenisation treatment. Mater. Charact. 2002, 48, 379-392. [CrossRef]

39. Ralston, K.D.; Birbilis, N.; Weyland, M.; Hutchinson, C.R. The effect of precipitate size on the yield strength-pitting corrosion correlation in Al-Cu-Mg alloys. Acta Mater. 2010, 58, 5941-5948. [CrossRef]

40. Pogatscher, S.; Kozeschnik, E.; Antrekowitsch, H.; Werinos, M.; Gerstl, S.S.A.; Loffler, J.F.; Uggowitzer, P.J. Process-controlled suppression of natural aging in an Al-Mg-Si alloy. Scripta Mater. 2014, 89, 53-56. [CrossRef]

41. Guan, L.; Zhang, B.; Wang, J.Q.; Han, E.H.; Ke, W. The reliability of electrochemical noise and current transients characterizing metastable pitting of Al-Mg-Si microelectrodes. Corros. Sci. 2014, 80, 1-6. [CrossRef]

42. Dong, C.F.; Sheng, H.; An, Y.H.; Li, X.G.; Xiao, K.; Cheng, Y.F. Corrosion of 7A04 aluminum alloy under defected epoxy coating studied by localized electrochemical impedance spectroscopy. Prog. Org. Coat. 2010, 67, 269-273. [CrossRef]

43. Ding, X.F.; Sun, J.; Ying, J.; Zhang, W.D.; Ma, J.H.; Wang, L.C. Influences of aging temperature and time on microstructure and mechanical properties of 6005A aluminum alloy extrusions. Trans. Nonferrous. Met. Soc. China 2012, 22, s14-s20. [CrossRef]

44. Alexopoulos, N.D.; Charalampidou, C.; Skarvelis, P.; Kourkoulis, S.K. Synergy of corrosion-induced micro-cracking and hydrogen embrittlement on the structural integrity of aluminium alloy (Al-Cu-Mg) 2024 . Corros. Sci. 2017, 121, 32-42. [CrossRef]

45. Gruenberg, K.M.; Craig, B.A.; Hillberry, B.M.; Bucci, R.J.; Hinkle, A.J. Predicting fatigue life of pre-corroded 2024-T3 aluminum from breaking load tests. Int. J. Fatigue 2004, 26, 615-627. [CrossRef]

46. Dong, P.; Sun, D.; Li, H. Natural aging behaviour of friction stir welded 6005A-T6 aluminium alloy. Mater. Sci. Eng. A 2013, 576, 29-35. [CrossRef]

47. Nejadseyfi, O.; Shokuhfar, A.; Dabiri, A.; Azimi, A. Combining equal-channel angular pressing and heat treatment to obtain enhanced corrosion resistance in 6061 aluminum alloy. J. Alloy. Compd. 2015, 648, 912-918. [CrossRef]

(C) 2019 by the authors. Licensee MDPI, Basel, Switzerland. This article is an open access article distributed under the terms and conditions of the Creative Commons Attribution (CC BY) license (http:/ / creativecommons.org/licenses/by/4.0/). 